\title{
Effects of the financial crisis and low interest rate environment on interest rate pass-through in Czech Republic, Hungary and Romania
}

\author{
JÁNOS ZOLTAN VARGA* (1)
}

Faculty of Economics and Business Administration, University of Szeged, Kálvária sgt. 1, Szeged, H-6725 Hungary

Received: February 5, 2020 • Revised manuscript received: June 24, 2020 • Accepted: November 18, 2020

(c) 2021 The Author(s)

\begin{abstract}
In order for monetary policy's interest rate channel to operate smoothly and effectively, the relevant retail interest rates of the real economy should react quickly and follow the movements of the prime rate. It has been observed that this connection has weakened since the financial crisis and it was suggested that the so called Weighted Average Cost of Liabilities (WACL) might be a better proxy for the banks' marginal costs than the prime rate or interbank rate. In this study the WACL for Czech Republic, Hungary and Romania is calculated by applying cointegration tests and ARDL models. I examined whether their long-run relationships with the retail loan rates are more stable. Results: 1. Using the WACL instead of the interbank rate yields slightly more stable long-term relationships with the retail loan rates, and the WACL has been proved to be somewhat more stable than the interbank rate. 2. The interest rate pass-through has been efficient for the household loan rates in all three countries, but only in Romania for the corporate loan rates. 3 . The results suggest that the central banks can effectively influence the commercial banks' financing costs even in a low interest rate environment, although this cost represents only one component of the loan rates, and the movements of other components can offset the changes of the prime rate.
\end{abstract}

\section{KEYWORDS}

monetary policy, bank lending, banks, interest rates, autoregressive distributed lags

JEL CLASSIFICATION INDICES

G210, E520, C540

*Corresponding author. E-mail: vjz@eco.u-szeged.hu 


\section{INTRODUCTION}

During the last couple of decades, the main tool of monetary policy in the developed countries was interest rate steering. The central banks tried to influence national retail rate levels (and consequently the country's economic activity) by setting the interest rate on some financial asset or liability issued by them. In order for the interest rate and credit channel of monetary policy to operate smoothly and effectively, the relevant interest rates of the real economy should react quickly and follow the movements of the base rate. However, during recent years it has been demonstrated that this pass-through effect was not perfect, the loan and deposit rates do not necessarily move perfectly with the base rate or some relevant short-term interbank rate, and the break-down of the interest rate pass-through (IP henceforward) is seemingly associated with the financial crises (Török - Konka 2018). It has been suggested that instead of using the base rate or interbank rate, the financing cost of the lending rate is more closely connected to the weighted average cost of liabilities (WACL), and it is more relevant for banks in pricing their loans.

The aim of this article is to investigate the interest rate pass-through process in Czech Republic, Hungary and Romania, compute the WACL and test whether its relationship with the retail lending rates is more stable than that of the interbank rate. Recently, the WACL was constructed for the euro area (EA) countries, for Poland by Illes et al. (2015) and Kapuscinski Stanislawska (2016), and we intended to extend the scope and study the possible effects for other non-euro area EU member countries.

The structure of the study is the following: at first the banks' pricing behavior, the reasoning behind the WACL approach and the applied methodology are briefly discussed. After that the relevant time series (interbank and loan rates, spreads and the constructed WACL for the selected countries) are presented and followed by the formal tests of monetary policy's interest rate channel.

\section{BACKGROUND}

According to the marginal cost pricing model, banks, like any other profit-oriented firm must consider the marginal costs of their operations when pricing their products. Hence, the relationship between lending rate and marginal cost price (this refers to market interest rate) can be captured by the following equation:

$$
i=\alpha+\beta r
$$

where $i$ is the bank's lending rate, $\alpha$ is markup constant (at the end of this section the issue of the non-constant markup rate will be addressed), $r$ is market rate and represents the marginal costs of intermediation and $\beta$ is a sensitivity coefficient (Rousseas 1985; de Bondt 2005). Usually, it is assumed that the marginal cost of the banks' lending activity is either some reference rate or the interbank rate. Therefore, it is expected that a given country's relevant loan rate and the reference rate (or the interbank rate which can serve as a proxy) move together in the long-run, that is, they are cointegrated. However, there is growing empirical evidence that, especially after the 2008 financial crisis, this pass-through process has not been perfect in many countries. ${ }^{1}$

\footnotetext{
${ }^{1}$ ECB (2009), Blot - Labondance (2013), Aristei - Gallo (2014) and von Borstel et al. (2016) documented for the Euro area (EA), Gambacorta et al. (2015) for Italy, Spain, United Kingdom and USA, Havranek et al. (2015) and Andries Billon (2016) for Czech Republic, and Varga (2016) for Hungary that the IP had been impaired by the financial crisis.
} 
It has been proposed by Illes et al. (2015) that the interbank rate or prime rate might not be the best proxy of the banks' marginal cost and the observed weakened long-term relationship between the prime rates and retail rates might be a consequence. They suggested that using the so called WACL might perform better and might represent the funding costs of commercial banks more accurately. They tested this hypothesis on data for the EA Member States and found that the pricing behavior of banks did not substantially change after the crisis and in fact the relationship between the retail rates and WACL has been stable. Following this research, Kapuscinski - Stanislawska (2016) studied the Polish IP and arrived at a similar conclusion.

The WACL is a weighted average of the interest rates at which commercial banks can obtain funding:

$$
W A C L=\sum_{i=1}^{n} w_{i} r_{i}
$$

where $r_{i}$-s are new business interest-rates on different liabilities of the banks, and $w_{i}$ is the proportion of that liability in total liabilities (outstanding stocks of liabilities). Using the stock of outstanding liabilities and new business interest rates in the calculation of WACL implicitly assumes that the current liability structure is a good predictor or proxy for the liability structure of the near future. The assumption is reasonable if one considers that changing the composition of liabilities for a bank is a slow process, since there are many items on the liability side of the balance sheet that have a maturity much longer than overnight, in fact more than a year or so. That explains the hybrid characteristics of WACL, i.e., stock liability structure and flow interest rate statistics.

So far, the markup $\alpha$ in (1) was assumed to be constant. However, this is not necessarily the case: the theoretical models and empirical findings suggest that the margin is subject to changes and shifts. For instance, one of the most influential models on the topic by Ho - Saunders (1981) assumed that the banks act as risk-averse dealers in deposit and loan markets. According to their model, the interest rate spread consists of two terms. The first term expresses the market structure, that is, if the market demand and supply for loans and deposits are inelastic, the bank is able to charge higher margins. The second term depends on three factors: the management's risk aversion, the size of the transactions and the volatility of interest rates. This implies that these factors can influence the spread of banking interest rates and had these factors change the margin would change as well. The model was later extended by (among others) Allen (1988), incorporating loan heterogeneity into the model, and it was found that due to the portfolio effect, the spread might be reduced when the cross-elasticities of bank products exist. Angbazo (1996) introduced default risk and showed that the banks with more risky loans tend to charge higher margins. Entrop et al. (2015) augmented the Ho - Saunders model with interest rate risk and found that higher maturity mismatch of loans and deposit leads to higher margins.

Wong (1997) applied industrial organization approach to show that market structure, operating costs and the exposure of credit and interest rate risk have positive relationships with the interest rate spread. Freixas - Rochet (2008) took into account the possible effects of credit risk and found that the firms' debt to equity ratio, the volatility of their assets and the duration of the loan determine the margins. Empirical studies corroborated one or more of the above models' predictions: for example, Angbanzo (1997), Saunders - Schumacher (2000), LopezEspinosa et al. (2011), Entrop et al. (2015) used data for 7 OECD countries, the USA, the German banking system and 15 developing and developed countries, respectively. 
The determinants of the interest rate margin are not the subject of our analysis, but from the above it is already clear that changes in these factors can change the spread, thereby they can possibly impair the IP. For example, consider a situation in which the central bank cuts the reference rate by 50 basis points, but parallel to this decision, the bank's risk perception shifts, thus increasing the interest rate spread. The net effect on the retail interest rate might be close to zero, making the IP less effective. This points to the fact that the funding costs of loans is only one (albeit very important) aspect of the pricing of the loan, but that the variations of the margins should not be ignored either.

\section{DATA AND METHODOLOGY}

\subsection{Data}

In order to examine the IP, selected retail loan rates, WACL and interbank rates are needed. For loan rates, the new business interest rates on over 1 million-euro loans to nonfinancial corporations, and interest rates on loans to household for house purchasing were considered. The interbank rate is the proxy for market rate, and monthly average of overnight interbank rates are used here in concordance with the literature (see e.g., Gambacorta et al. 2015). It should be noted, however, that in Hungary the spread between the prime rate and the interbank rate has widened since the end of 2008. The reason for this is the surge in excess interbank liquidity after that the country obtained a loan from the trio of IMF, European Commission and the World Bank at the onset of the financial crisis in 2008. Most of the loan was used to refinance sovereign debt denominated in local currency. The excess liquidity in turn increased the liquidity supply in the interbank market, thereby pushing the interbank rate downwards. Thus, the spread between loan rate and interbank rate is significantly higher than the spread between loan rate and prime rate (Varga 2016). Consequently, the spread over interbank rate is distorted, and for this reason one could argue that, from the perspective of interest rate transmission to retail rates, using the prime rate is more appropriate. However, for the sake of comparison, the interbank rate was used in the case of Hungary as well.

In computing the WACL, I took a banking sector level approach, that is, I used the monetary statistics provided by the central banks and calculated different proportions of liabilities for the whole banking sector. Following Kapuscinski - Stanislawska (2016), only liabilities denominated in local currency are considered. Having obtained weights for the liabilities, these are multiplied by the corresponding interest rates. Central banks provide statistics for the new business interest rates on deposits for different economic sectors (households, non-financial corporations and financial corporation other than MFIs), therefore they can be used in a straightforward manner. As for government (local and central) deposits, due to the lack of specified interest rate statistics, the rates applied for non-financial corporations were used. In case of debt securities issued by banks, I found the interest rate to be paid on them in most cases is fixed to some interbank rate, hence the one-year interbank rate was used as financing cost for calculating the WACL. It should be noted however, that the markup of debt securities on the interbank rate is not zero, thus using only the interbank rate as the cost could lead to underestimation of the true WACL. Having said that, the proportion of debt securities, as can be seen in the next section, is relatively small in all three countries, so adding some markup constant to the interbank rate would not 
change the WACL significantly, and, what is more, it would only change the level of WACL, not its evolution.

The time series start at 2003, 2004 and 2007 for Hungary, Czech Republic and Romania, respectively, and end in October 2017. Monthly values are used in all cases, the data being obtained from the corresponding central banks databases. ${ }^{2}$

\subsection{Cointegration}

To test the efficiency of interest-rate transmission formally, one usually looks for cointegrating relationships between the variables in question. Economic time series often exhibit non-stationarity and estimating regression between such variables can lead to spurious regressions, and the test statistics will be unreliable. Although if the time series are related to each other in some way, it can often be observed that they exhibit a common trend and it is possible to find a linear combination of them which would be stationary (that is, the variables are cointegrating). So, the usual way to investigate IP is first to test the stationarity of the variables involved in the analysis, using the well-known unit-root tests, such as the Augmented Dickey-Fuller or the PhilipsPerrion tests. If the null hypothesis of non-stationarity cannot be rejected, the analysis can proceed by testing the cointegration relationships by applying cointegration tests such as the Engle-Granger or Johansen-test.

The problem with this approach is that the economic time series often contain structural breaks which can lead to under-rejection of the non-stationarity null hypothesis using the standard unit root tests (Perron 1989; Maddala - In-Moo 1999; Paleckova 2019). As a response to the financial crisis, interest rates have tended to decrease and reached the historically low levels. Indeed, in Fig. 2, the evolution of interest rates and WACL can be seen and they do exhibit signs of structural breaks. Therefore, it is reasonable to assume that there have been structural changes in the interest-rate-related time series, hence special unit root test should be carried out which could handle the regime shifts and changes. For this reason, the unit-root test proposed by Vogelsang - Perron (1998) is applied beside the usual unit-root tests to take into account the possible effects of structural changes. The advantage of this test is that it does not require an exogenously set break date but is able to find it endogenously; thereby it does not depend on the priori assumptions concerning the exact date of structural change.

The next step in the analysis is to check whether there are any cointegrating relationships between the interbank rate or WACL and the loan rates. As mentioned above, cointegration occurs when a linear combination of the given variables is stationary; in other words, the variables have a common stochastic trend (Lütkepohl - Krätzig 2006). When the time series are cointegrated, the cointegration regression can be considered to be the long-run equilibrium model between the variables. The widely used Johansen-test and Engle-Granger test were carried out to inspect whether there is a long-term relationship between the given variables. For each country, four possible cointegrating relationships were considered: the interbank rate with corporate loan rate and household loan rate, and WACL with corporate loan rate and household loan rate.

\footnotetext{
${ }^{2}$ Hungarian Central Bank - MNB, Czech National Bank - CNB, National Bank of Romania - NBR.
} 
However, one notable problem can occur with the traditional cointegration tests when the order of integration of variables differs. The seminal articles on cointegration by Engle - Granger (1987) and Johansen (1991) assumed that both (all) series are I(1), i.e. they are difference stationary, that is differencing the series transforms them to stationary. However, it may very well be the case that one of the series is not $I(1)$ or the order of a series is uncertain thanks to the size distortions and low power accompanying the usual unit root tests (see e.g., Maddala - In-Moo 1999). This is the unbalanced equation problem and one consequence is that the critical values for hypothesis testing might not be reliable. One way to handle the situation is to use Autoregressive Distributed Lags (ARDL) models as proposed by Pesaran et al. (2001). As will be seen in the next section, the breakpoint unit root tests indicate that some of the series are $I(0)$ and some are $I(1)$, therefore in addition to the Engle-Granger and Johansen tests, ARDL models had been carried out to investigate the long run relationship between the variables and the short run dynamics of IP. An ARDL $(\mathrm{p}, \mathrm{q})$ model in general is the following:

$$
y_{t}=\alpha_{0}+\alpha_{t} t+\sum_{i=1}^{p} \phi_{i} y_{t-1}+\sum_{j=1}^{q} \theta_{j} x_{t-j}+\varepsilon_{t}
$$

where $\varepsilon_{t} \sim$ iid $\left(0, \sigma^{2}\right)$ disturbance, $\alpha_{0}$ is the constant, and $\alpha_{t}, \phi_{i}$ and $\beta_{j, l}$ are the coefficients of the linear trend, lags of the dependent variable and the regressors, respectively. Let $\Delta y_{t}=y_{t^{-}} y_{t-1}$, now, (3) can be transformed into

$$
\Delta y_{t}=a_{0}+a_{1} t+\alpha y_{t-1}+\theta x_{t-1}+\sum_{j=1}^{p-1} \gamma_{j} \Delta y_{t-j}+\sum_{j=0}^{q-1} \psi_{j} \Delta x_{t-j}+u_{t}
$$

where $\alpha=-(1-\phi)$. Let $\beta=-\theta / \alpha$, then (4) can be rearranged as:

$$
\Delta y_{t}=a_{0}+a_{1} t+\alpha\left(y_{t-1}-\beta x_{t-1}\right)+\sum_{j=1}^{p-1} \gamma_{j} \Delta y_{t-j}+\sum_{j=0}^{q-1} \psi_{j} \Delta x_{t-j}+u_{t}
$$

where $\beta$ is the long-term parameter, and the error correction (EC) term, which is also the cointegration relationship, is the following:

$$
E C=y_{t-1}-\frac{\theta}{\alpha} x_{t-1}
$$

Pesaran et al. (2001) proposed bounds test and the corresponding critical values for the EC's coefficient and showed that these tests are in fact consistent. $\mathrm{H}_{0}: \alpha=\theta=0$ and rejecting the null hypothesis would indicate the cointegrating relationships between the variables.

It is important to emphasize that the lack of cointegration does not mean that the interbank rate or WACL cannot influence the commercial rates. From an economic standpoint this would only mean that the interest-rate pass through is not smooth and efficient. Vector Autoregression (VAR) models with impulse response can be applied to investigate further the IP process. ${ }^{3}$ However, in this study, the attention is restricted to the cointegrating relationships.

\footnotetext{
${ }^{3} \mathrm{An}$ anonymous reviewer is thanked to point out this issue.
} 


\section{RESULTS}

\subsection{Liability composition}

The liability structure of the commercial banks can be seen in Fig. 1. Not surprisingly, in all the three countries the household deposits represent the most important funding for banks; their proportions ranging from 35 to $60 \%$ of total liabilities. The Czech Republic had the most stable liability structure, the main components barely changed during the period between 2004 and 2017, with household deposits being the most important; around 50\% of the banks' liabilities come from this source. The share had been on a mild decline during the pre-crisis period, fell below $50 \%$, but started to increase after that. Similar trajectories were observed in other European countries (Illes et al. 2015; Kapuscinski - Stanislawska 2016), suggesting that commercial banks tended to rely more on stable financing sources as a response to the global financial disturbances. The deposits of non-financial corporations were just below $20 \%$ and interbank loans and debt securities made up around $10 \%$, respectively.

In Hungary, the picture is different: while household deposits still constitute the largest proportion of liabilities, their importance has weakened, and at the end of 2017, their weight fell as low as $35 \%$. One of the most important factors contributing to this decline is the government's highvolume bond issuance to households. As mentioned earlier, Hungary had to resort to the IMF in order to avoid sovereign default and used its loan mainly to refinance sovereign debt which resulted in a huge surge in the share of foreign currency denominated debt in the debt structure (which was already significant: around $40 \%$ before the crisis, and almost $70 \%$ after exercising the IMF loan). ${ }^{4}$ The need to refinance the relatively high level of foreign debt carries substantial risk, and the government decided to decrease this vulnerability by refinancing the maturing foreign currency denominated debt with the Hungarian Forint denominated debt. The process involved issuing bonds directly to the household and making them attractive by paying a higher interest rate than one could obtain on bank deposits. The household deposits, in turn, were shifted from bank deposits toward government debt instruments. After the financial crisis the proportion of both interbank loans and corporate deposits increased, and the former can be explained partly by the high interbank liquidity discussed above. Debt securities have made up around 10 per cent of the liabilities.

As for Romania, the share of household deposits was already increasing before the crisis, from $40 \%$ level, and staying in the range of between 50 and $60 \%$ during the post crisis period. One of the direct consequences of the financial turmoil in 2008-2009 was the sudden drop in the proportion of corporate deposits (around 10 percentage point), but this has recovered since and again reached almost $40 \%$.

In all three countries the proportion of total overnight deposits (including households, nonfinancial corporations and governments) comprise a substantial share of deposits (ranging from around $40-60 \%$ ), thereby providing a cheap albeit liquid financing source for the banking sector.

\subsection{WACL and loan rates}

To obtain the WACL, the liability weights are to be multiplied with the appropriate interest rate. The evolution of WACL and loan rates can be seen in Fig. 2. In the Czech Republic the WACL

${ }^{4}$ For reasons that led to Hungary's de facto sovereign default in 2008, see e.g. Kovács (2009). 
Czech Republic

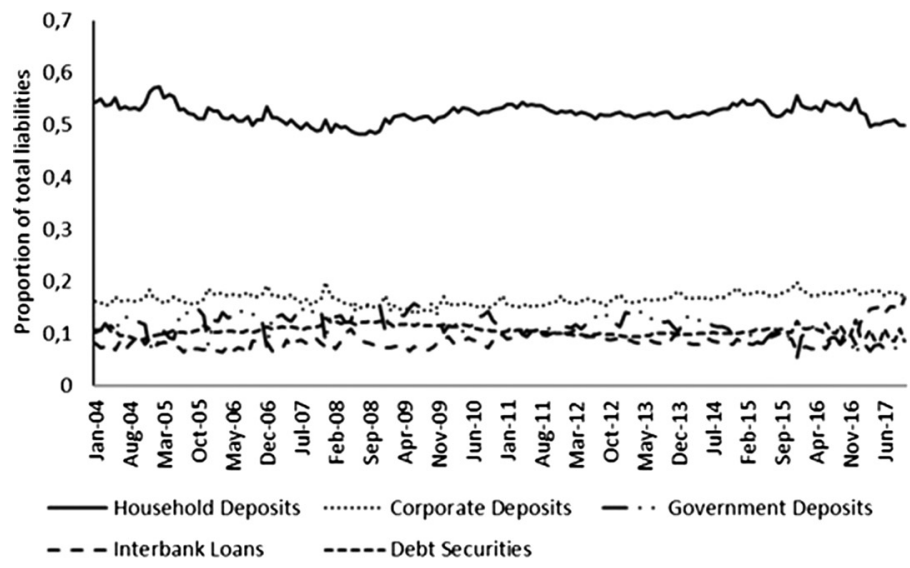

Hungary

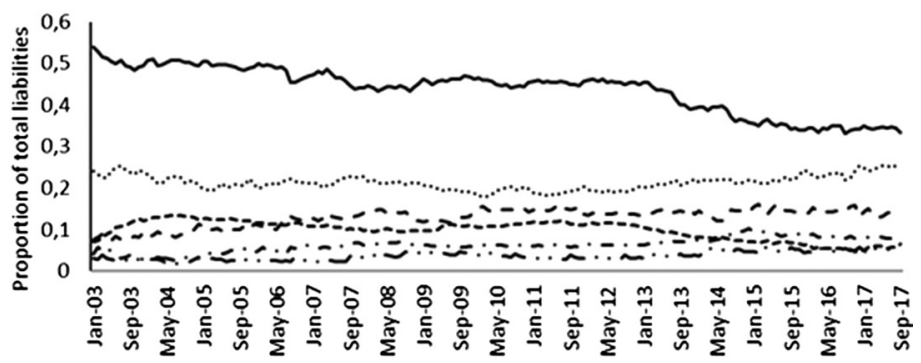

Household Deposits

------Debt Securities

- - Interbank Loan

Romania

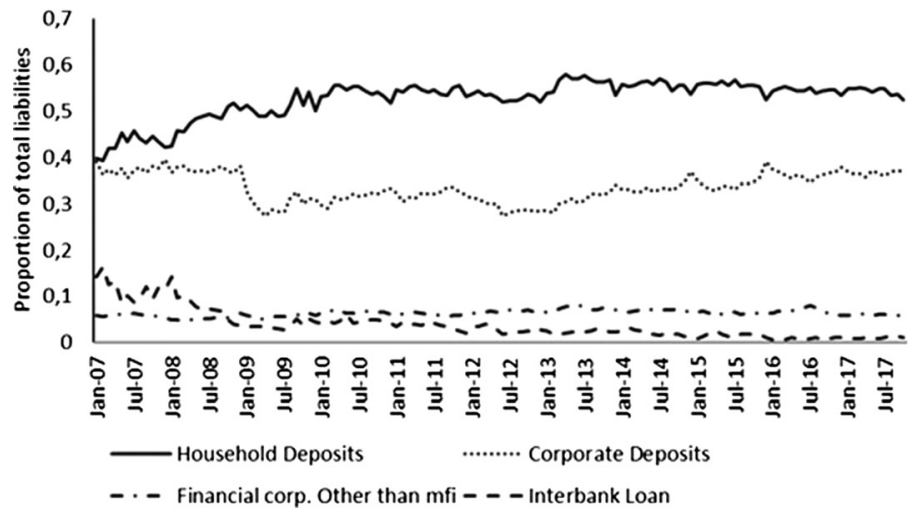

Fig. 1. The evolution of the liability compositions, proportion of total liabilities Source: CNB, MNB, BNR and own construction. 


\section{Czech Republic}

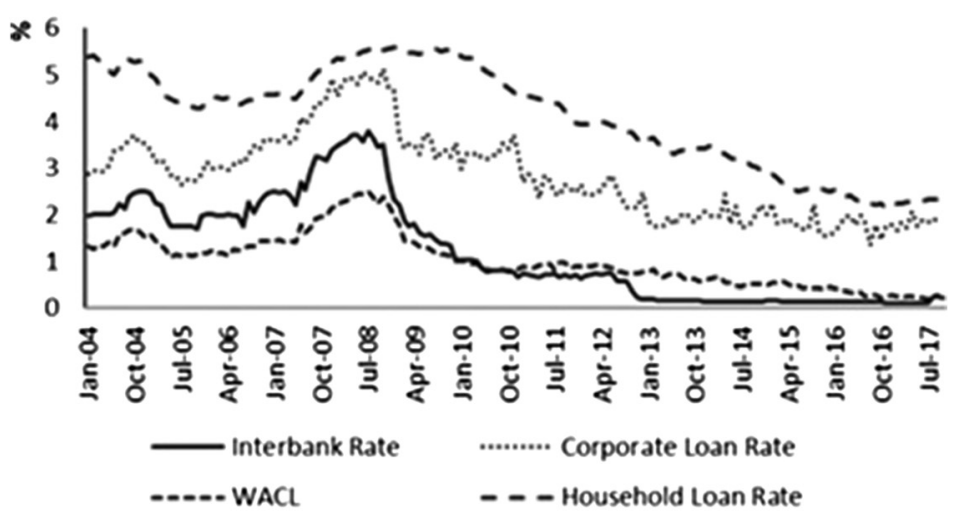

Hungary

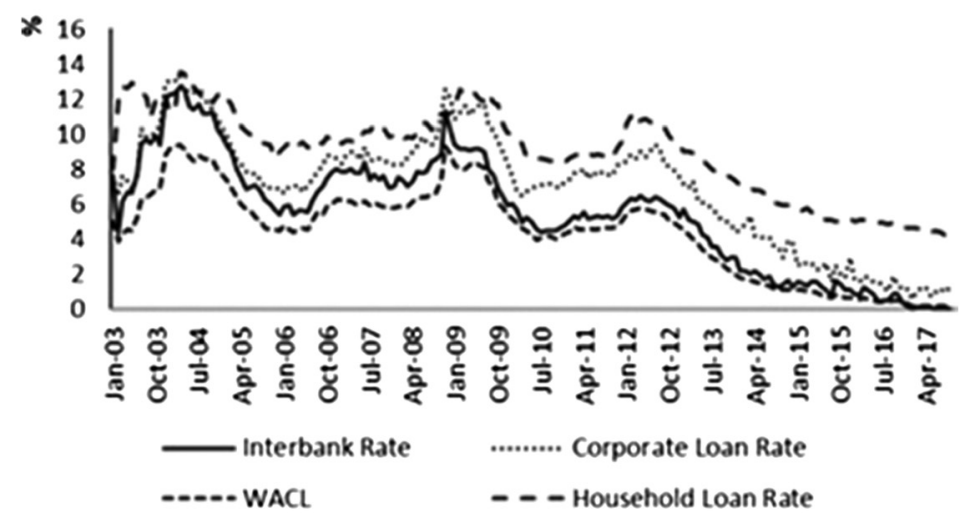

Romania

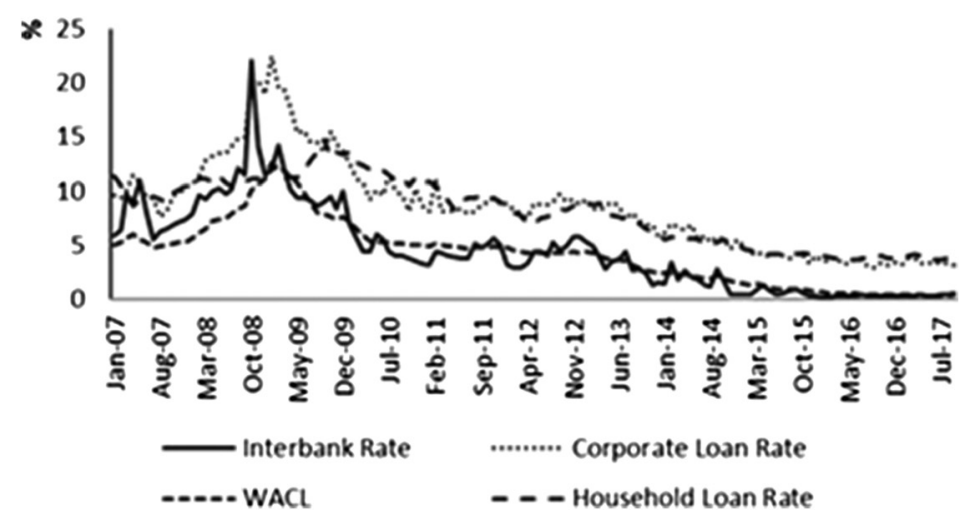

Fig. 2. The evolution of WACL, interbank rate and loan rates Source: CNB, MNB, BNR and own construction. 
had been lower than the interbank rate during the pre-crisis period but has been higher since then. This has been mainly due to the fact that the spread of household deposits on interbank rate had been negative until around 2010 but has been constantly positive since. This means that the household deposit rate has been fairly stable during the period, while in Hungary, the rate on household deposits has been lower than the interbank rate, following that closely. Since their share in the liabilities have been around $50 \%$ on average, the WACL itself has been lower than the interbank rate in the whole period (the post-crisis deviation is marginal though), but the two are moving together very closely. The difference between the two has been marginal since in Romania, the WACL and interbank rate basically have been moving together with the WACL. The case of the Czech Republic highlights that the level of interest rate is important: in the other two countries the pre-crisis interest rates were significantly higher. They converged to each other post-crisis, so the decline was steeper in Romania and Hungary, and that explains why the interest rates in the Czech Republic seem more stable.

Non-financial corporate loan rates reached their maximum during the financial crisis and basically have been declining since. Indeed, they are currently at historically low levels in all three countries discussed here. In Hungary and Romania, the loan rate, WACL and interbank rates are generally moving together, while in the Czech Republic the relationship between corporate loan rate and interbank rate is stronger, due to the fact discussed above, and the evolution of Czech WACL has been somewhat different from that of the interbank rate.

Fig. 3 is a transformation of Fig. 2, that is, it shows the spreads of corporate loan rates over interbank rate and WACL. Basically, in all three countries the spread on interbank rate had constantly increased before and at the onset of the crises, while the spread on WACL has been somewhat more stable, and in fact, on average it fell below the pre-crisis level. Both spreads have declined everywhere since their peak after the crisis probably due to the historically low interest rate environment. Over the last 4-5 years, the spreads have been moving closely together, suggesting that the difference between spreads is partly influenced by the absolute level of interest rates. Interestingly, the spread over WACL and the spread over interbank rates usually have been very close to each other since the crisis, with the only exception being Hungary, where the spread over WACL has been constantly higher, especially before 2013.

Regarding the interest rate on household loans for house purchasing, the evolutions of spreads are little bit different: the spreads had already been declining before the crisis, but then started to increase sharply as a consequence of the financial disturbances and spiked around the end of 2009 (see Fig. 4). The spreads have been decreasing since then, except for Hungary where the spreads stayed at a relatively high level, and in fact has even increased. Aczél et al. (2016) argued that the main reason behind this is that the proportion of loans with long-term fixed interest rate is relatively high (around 50\%) in Hungary, and the spread on those loans is higher than the average in the region, meaning customers pay a higher premium for stable and predictable installments.

\subsection{Interest-rate pass-through}

As discussed in Section 2 before we can proceed to cointegration analysis, the stationarity of the time series must be checked. The test results of the Vogelsang-Perron break point, the ADF and the PP can be seen in Table 1. Interestingly, the traditional tests cannot reject the null hypothesis, implying that all the time series are non-stationary. In contrast, the break point unit 


\section{Czech Republic}

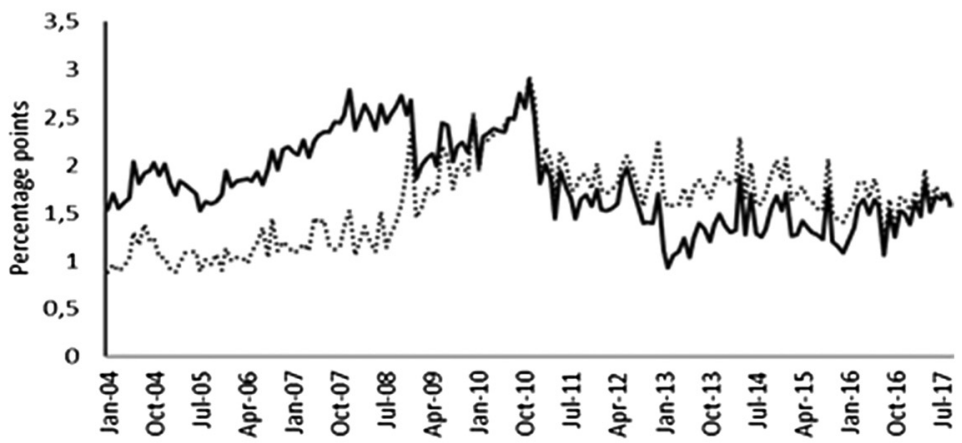

Hungary

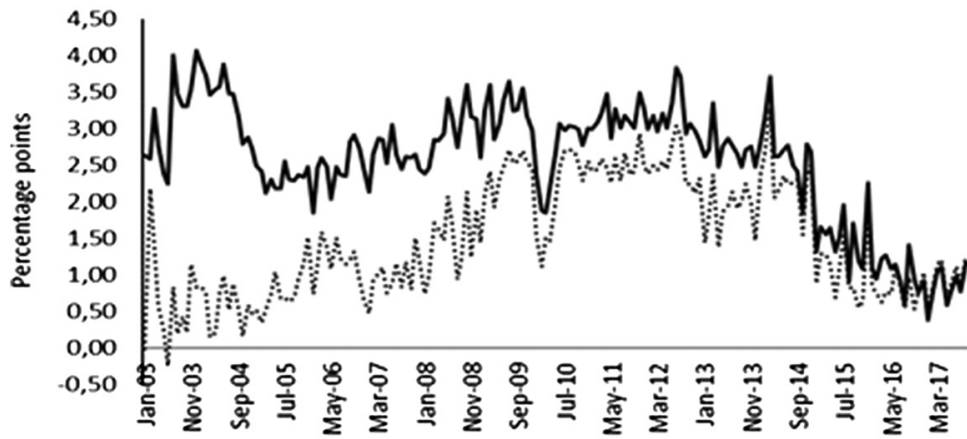

Romania

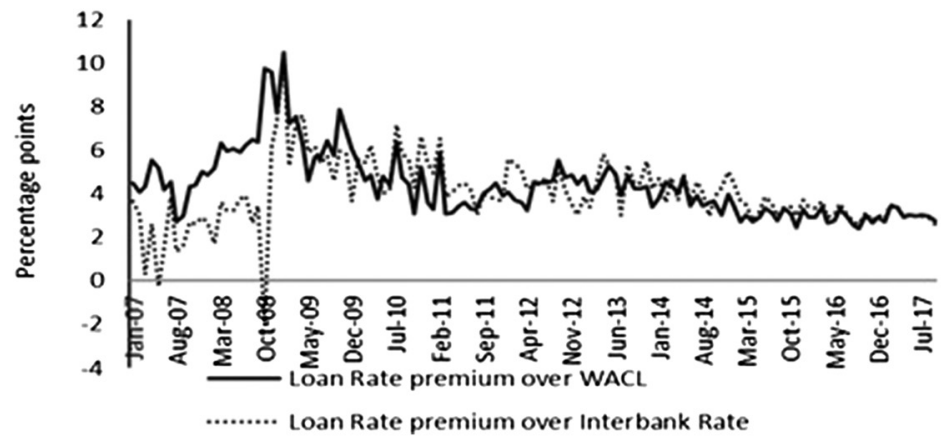

Fig. 3. The evolution of corporate loan rate spreads

Source: CNB, MNB, BNR and own construction.

root test indicates that 8 of the 12 time series are in fact stationary with a break in the data (in 6 cases the results are significant even at $1 \%$ level). This is important since the standard cointegration tests are unreliable for unbalanced equations.

For the above reasons, the ARDL model is better suited to examine the long-term relationships of the variables. The test results can be seen in Table 3. In addition, the ARDL model 


\section{Czech Republic}

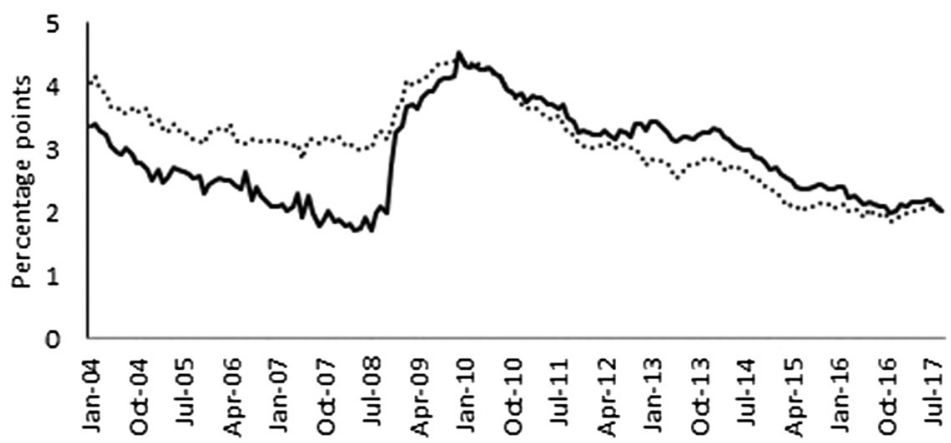

Hungary

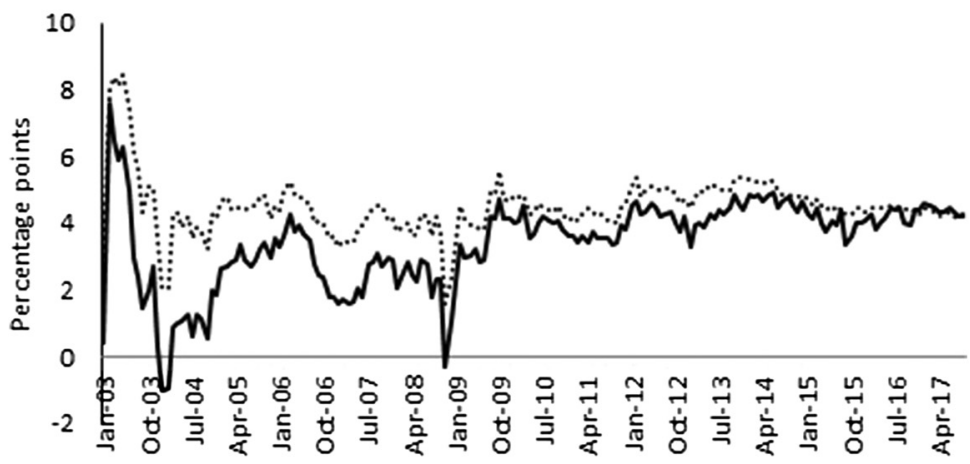

Romania

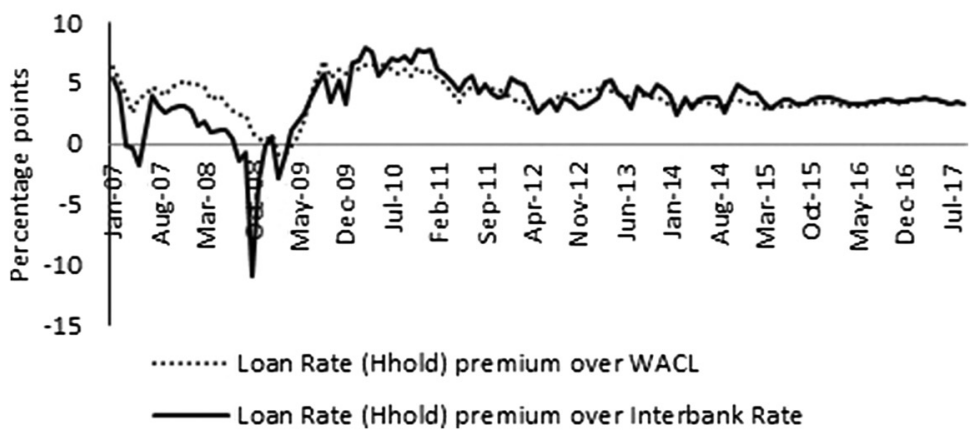

Fig. 4. The evolution of household loan rate spreads

Source: CNB, MNB, BNR and own construction.

with a crisis dummy variable was estimated (third column) to account for the possible changes in the data due to the crisis. Moreover, for comparison purposes, the Johansen and the EngleGranger tests were carried out as well, the results are displayed in Table 2. 
Table 1. Unit Root tests

\begin{tabular}{|l|l|c|c|c|}
\hline Country & \multicolumn{1}{|c|}{ Time series } & Break Point Unit Root & ADF & PP \\
\hline \multirow{5}{*}{ Hungary } & WACL & $-5.99^{* * *}$ & -0.582431 & -0.799214 \\
\cline { 2 - 5 } & Loan Rate (Corp.) & -3.81 & -0.41251 & -0.766459 \\
\cline { 2 - 5 } & Loan Rate (Hhold) & $-5.24^{* *}$ & -0.70563 & -0.724023 \\
\cline { 2 - 5 } & Interbank Rate & $-7.99^{* * *}$ & -0.581947 & -0.838534 \\
\hline Czech Republic & WACL & -3.21 & -2.623 & -0.945901 \\
\cline { 2 - 5 } & Loan Rate (Corp.) & $-4.05^{*}$ & -0.955368 & -1.169111 \\
\cline { 2 - 5 } & Loan Rate (HHold) & $-9.66^{* * *}$ & -0.41216 & -0.230224 \\
\cline { 2 - 5 } & Interbank Rate & -6.37 & -1.442749 & -1.006835 \\
\hline \multirow{5}{*}{ Romania } & WACL & $-5.81^{* * *}$ & -1.282144 & -0.747615 \\
\cline { 2 - 5 } & Loan Rate (Corp.) & $-5.45^{* *}$ & -1.284174 & -0.89882 \\
\cline { 2 - 5 } & Loan Rate (HHold) & -2.51 & -0.605741 & -0.675612 \\
\cline { 2 - 5 } & Interbank Rate & $-5.67^{* * *}$ & -1.535654 & -1.616276 \\
\hline
\end{tabular}

Note: Null-hypothesis: the time series is not stationary. ${ }^{* * *},{ }^{* *},{ }^{*}$ indicate significant levels at $P<0.01, P<0.05$, $P<0.1$, respectively.

Source: Own calculations.

Table 2. Cointegration tests

\begin{tabular}{|c|c|c|c|}
\hline & Variables & Johansen test & Engle-Granger test \\
\hline \multirow[t]{4}{*}{ Hungary } & WACL - Loan Rate (Corp.) & - & $*$ \\
\hline & Interbank - Loan Rate (Corp.) & - & - \\
\hline & WACL - Loan Rate (HHold.) & $* * *$ & $* * *$ \\
\hline & Interbank - Loan Rate (HHold.) & $* * *$ & $* * *$ \\
\hline \multirow[t]{4}{*}{ Czech Republic } & WACL - Loan Rate (Corp.) & - & - \\
\hline & Interbank - Loan Rate (Corp.) & - & - \\
\hline & WACL Loan - Rate (HHold.) & - & - \\
\hline & Interbank - Loan Rate (HHold.) & $* *$ & - \\
\hline \multirow[t]{4}{*}{ Romania } & WACL - Loan Rate (Corp.) & $* *$ & $* * *$ \\
\hline & Interbank - Loan Rate (Corp.) & $* *$ & $* * *$ \\
\hline & WACL - Loan Rate (HHold.) & $* * *$ & $* *$ \\
\hline & Interbank - Loan Rate (HHold.) & - & - \\
\hline
\end{tabular}

Note: Null-hypothesis: no cointegration. ${ }^{* * *},{ }^{* *},{ }^{*}$ indicate significant levels at $P<0.01, P<0.05, P<0.1$, respectively. Source: Own calculations. 
Table 3. ARDL cointegration analysis

\begin{tabular}{|l|l|c|c|}
\hline \multirow{4}{*}{ Hungary } & \multicolumn{1}{|c|}{ Variables } & ARDL f bound test & $\begin{array}{c}\text { ARDL f bound test } \\
\text { with shift dummy }\end{array}$ \\
\cline { 2 - 4 } & WACL - Loan Rate (Corp.) & 3.67 & $4.53 \ddagger$ \\
\cline { 2 - 4 } & Interbank - Loan Rate (Corp.) & 2.63 & 3.58 \\
\cline { 2 - 4 } & WACL - Loan Rate (HHold.) & $21.53^{* * *}$ & $21.63^{* * *}$ \\
\cline { 2 - 4 } & Interbank - Loan Rate (HHold.) & $5.93^{* *}$ & $6.65^{* *}$ \\
\hline \multirow{5}{*}{ Rzech Republic } & WACL - Loan Rate (Corp.) & $4.95^{*}$ & $4.69 \ddagger$ \\
\cline { 2 - 4 } & Interbank - Loan Rate (Corp.) & 2.45 & 3.34 \\
\cline { 2 - 4 } & WACL Loan - Rate (HHold.) & $6.46^{* *}$ & $6.86^{* *}$ \\
\cline { 2 - 4 } & Interbank - Loan Rate (HHold.) & $6.01^{* *}$ & $7.72^{* *}$ \\
\hline & WACL - Loan Rate (Corp.) & $13.27^{* * *}$ & $12.66^{* * *}$ \\
\cline { 2 - 5 } & Interbank - Loan Rate (Corp.) & $6.16^{* *}$ & $11.51^{* * *}$ \\
\cline { 2 - 5 } & WACL - Loan Rate (HHold.) & $9.73^{* * *}$ & $13.17^{* * *}$ \\
\cline { 2 - 5 } & Interbank - Loan Rate (HHold.) & $6.04^{* *}$ & $4.97^{*}$ \\
\hline
\end{tabular}

Note: Null-hypothesis: no long-term relationship. ${ }^{* * *},{ }^{* *},{ }^{*}$ indicate significant levels at $P<0.01, P<0.05$, $P<0.1$, respectively.

Source: Own calculations.

It can be seen from the test statistics that in Romania both tests were able to find cointegrating relationships, using the WACL and the interbank rate as well, for both loan rates. These suggest that the Romanian interest-rate pass through is operating efficiently, and the monetary authority is able to steer the retail interest-rates (these results are in concordance with the findings of Enache - Radu (2015)). The Johansen test yields similar results, except for the Interbank-rate - Corporate loan rate relation.

In Czech Republic and Hungary, the picture is different - long-term relationships were found for the household loan rates, but not for the corporate loan rates. It was suggested by Varga (2016) that in Hungary the excess interbank liquidity might account for the deviations of corporate loan rates from equilibrium. In fact, if the ARDL model for Hungary is augmented by the Hungarian interbank liquidity, the bound test indicates that the long-term relationship between the interbank rate and the corporate loan rate is restored. As for Czech Republic, Havranek et al. (2015) analyzing the Czech bank level data found that some banks try to smooth out the changes in the policy rate for their clients, thereby they are not following the base rate that immediately or closely. Interesting to note that, for Hungary, the ARDL test results are in agreement with the Johansen tests. As for Czech Republic, the Johansen test indicates a cointegrating relationship only between interbank rate and household loan rate.

The results suggest that the IP process for household loan rates was satisfactory in all three countries, but only in Romania for corporate loan rates. The possible answer for that probably involves recognizing several factors. One is that the actual level of the interest rates matters: in 


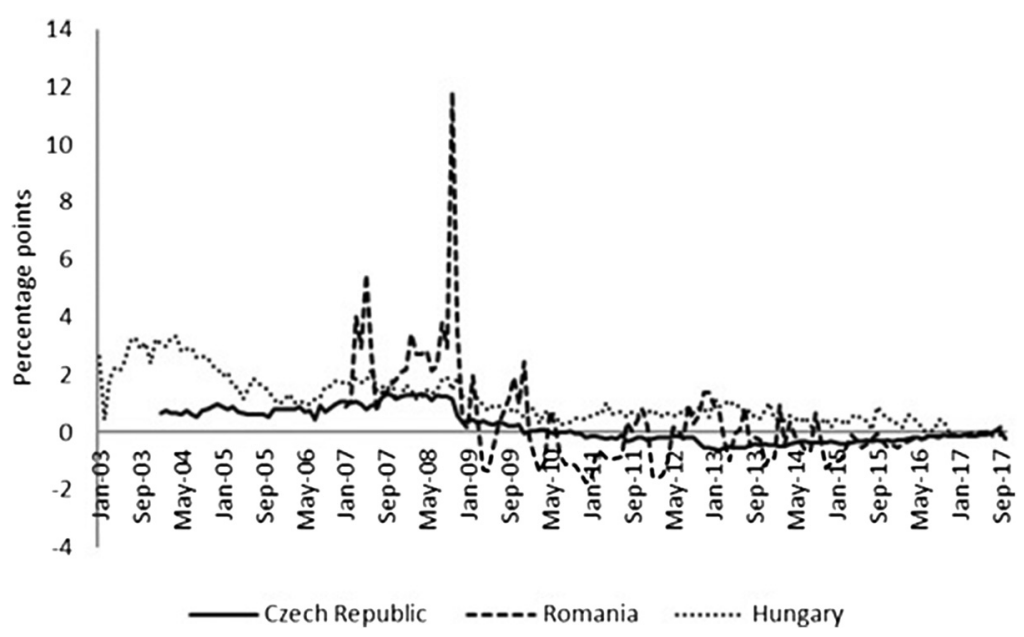

Fig. 5. The evolution of Interbank rate-WACL Source: CNB, MNB, BNR and own construction.

Czech Republic and Hungary household loan rates have been higher than the corporate loan rates, in Romania the level of the two has been roughly the same and at the level of the household rates observed in Hungary. So, it might be the case that when the financing cost are higher, a change in the financing costs can pass-through easier, because the size of the markup (denoted by $\alpha$ in (1)) relative to the financing costs is smaller. Hence, the change in the components of the markup (discussed in Section 2) cannot offset the change in the financing costs. On the other hand, when financing costs are relatively small, the markup constitutes a higher share of the retail rate. And the components of the markup can very much offset the changes in financing costs. This means that the monetary authorities still can and do influence the financing costs even in a low interest rate environment, but the markup can impair the pass-through process.

It is important to note that using the WACL instead of the interbank rate does yield better test statistics and slightly better overall results, although the number of long-term relationships found by using the WACL is not really different. These results show that the WACL can estimate the banks' funding costs somewhat better than the base rate or interbank rate. However, one caveat is in order: in Fig. 5, it can be seen that the WACL and the interbank rate in all three countries have moved closer together after the crisis. Thus, the interbank rate's inadequacy in representing the commercial banks' funding costs cannot account for the weakened long-term relationships observed in numerous countries after the recent financial turmoil. In order to gain a better understanding of the efficacy of the interest rate and credit channels, a more micro approach is needed, that is, the components that comprise the margin of retail interest rates should be studied using the individual bank level data.

\section{CONCLUSIONS}

In developed and developing countries, interest rate steering has been of central importance for monetary policy. This assumes that retail interest rates, through mainly the interest rate and 
credit channel, follow closely the changes in the base rate. After the 2008-2009 financial crisis, interest rate pass-through has seemed to be less efficient. I found that the Weighted Average Cost of Liabilities (WACL) was more stable during the studied period than the overnight interbank rate, and its long-term relationship is slightly better with respect to the retail rates. Nevertheless, the results are modest, and in fact, the deviation of WACL from interbank has been significantly lower since 2008-2009. The findings suggest that the observed impaired longterm relationships might be explained by changes in the components of the retail interest rate margins. Thus, it seems in a low interest-rate environment, the central banks can still influence the funding costs of commercial banks, although, conventional monetary policy tools might not be able to effectively affect the margins of retail interest rates. This implies that the monetary authority should also take into account the level of interest rates, the structure of banking market, the level of competition, the risk perception and risk aversion of bank managers.

\section{REFERENCES}

Aczél, Á. - Banai, Á. - Borsos, A. - Dancsik, B. (2016): A lakáshitelek felárát meghatárzó tényezők azonosítása a magyar bankrendszerben (Identifying the Determinants of Housing Loan Margins in the Hungarian Banking System). Hitelintézeti Szemle, 15(4): 5-44.

Allen, L. (1988): The Determinants of Bank Interest Margins: A Note. Journal of Financial and Quantitative Analysis, 23(2): 231-235.

Andries, N. - Billon, S. (2016): Retail Bank Interest Rate Pass-Through in the Euro Area: An Empirical Survey. Economic Systems, 40(1): 170-194.

Angbanzo, L. (1997): Commercial Bank Net Interest Margins, Default Risk, Interest-Rate Risk, and OffBalance Sheet Banking. Journal of Banking and Finance, 21(1): 55-87.

Aristei, D. - Gallo, M. (2014): Interest Rate Pass-Through in the Euro Area during the Financial Crisis: A Multivariate Regime-Switching Approach. Journal of Policy Modeling, 36(2): 273-295.

Blot, C. - Labondance, F. (2013): Business Lending Rate Pass-Through in the Eurozone: Monetary Policy Transmission Before and After the Financial Crash. Economic Bulletin, 2(1): 973-985.

Borstel, J. von - Eickmeier, S. - Krippner, L. (2016): The Interest Rate Pass-Through in the Euro Area during the Sovereign Debt Crisis. Journal of International Money and Finance, 68: 386-402.

de Bondt, G. J. (2005): The Interest Rate Pass-Through: Empirical Results for the Euro Area. German Economic Review, 6(1): 37-78.

ECB (2009): Recent Developments in the Retail Bank Interest Rate Pass-Through in the Euro Area. Monthly Bulletin, ECB, Frankfurt am Main, August.

Enache, R. - Radu, R. (2015): Interest Rate Pass-Through in Romania. Recent Empirical Evidence and Regional Comparisons. Occasional Papers, No. 16, National Bank of Romania.

Engle, R. F. - Granger, C. W. H. (1987): Co-Integration and Error Correction: Representation, Estimation and Testing. Econometrica, 55(2): 251-276.

Entrop, O. - Memmel, C. - Ruprecht, B. - Wilkens, M. (2015): Determinants of Bank Interest Margins: Impact of Maturity Transformation. Journal of Banking and Finance, 54: 1-19.

Freixas, X. - Rochet, J. C. (2008): Microeconomics of Banking. The MIT Press.

Gambacorta, L. - Illes, A. - Lombardi, M. J. (2015): Has the Transmission of Policy Rates been Impaired by the Global Financial Crisis? International Finance, 18(3): 263-280. 
Havranek, T. - Irsova, Z. - Lesanovska, J. (2015): Bank Efficiency and Interest Rate Pass-Through: Evidence from Czech Loan Products. Working Paper, No. 24, Institute of Economic Studies, Faculty of Social Sciences Charles University, Prague.

Ho, T. S. Y. - Saunders, A. (1981): The Determinants of Bank Interest Margins: Theory and Empirical Evidence. The Journal of Financial and Quantitative Analysis, 16(4): 581-600.

Illes, A. - Lombardi, M. - Mizen, P. (2015): Why Did Bank Lending Rates Diverge from Policy Rates After the Financial Crisis? Working Paper, No. 486, Bank for International Settlements.

Johansen, S. (1991): Estimation and Hypothesis Testing of Cointegration Vectors in Gaussian Vector Autoregressive Models. Econometrica, 59(6): 1551-1580.

Kapuscinski, M. - Stanislawska, E. (2016): Interest Rate Pass-Through in Poland since the Global Financial Crisis. Working Paper, No. 247, National Bank of Poland.

Kovács, Gy. (2009): Financial Stability and the Banking System, or the Imbalance of the Intermediary System. Public Finance Quarterly, 54(1): 50-68.

Lopez-Espinosa, G. - Moreno, A. - Perez de Garcia, A. (2011): Banks' Net Interest Margin in the 2000s: A Macro-Accounting International Perspective. Journal of International Money and Finance, 30(6): 12141233.

Lütkepohl, H. - Krätzig, M. (2004): Applied Time Series Econometrics. Cambridge: Cambridge University Press.

Maddala, G. S. - In-Moo, K. (1999): Unit Roots, Cointegration, and Structural Change. New York: Cambridge University Press.

Paleckova, I. (2019): Cost Efficiency Measurement Using Two-Stage Data Envelopment Analysis in the Czech and Slovak Banking Sectors. Acta Oeconomica, 69(3): 445-466.

Perron, P. (1989): The Great Crash, the Oil Price Shock, and the Unit Root Hypothesis. Econometrica, 57(6): 1361-1401.

Pesaran, M. H. - Shin, Y. - Smith, R. (2001): Bounds Testing Approaches to the Analysis of Level Relationships. Journal of Applied Econometrics, 16(3): 289-326.

Rousseas, S. (1985): A Markup Theory of Bank Loan Rates. Journal of Post Keynesian Economics, 8(1): 135144.

Saunders, A. - Schumacher, L. (2000): The Determinants of Bank Interest Rate Margins: An International Study. Journal of International Money and Finance, 19(6): 813-832.

Török, Á. - Konka, B. (2018): Episode or Hysteresis? Some Theoretical and Policy Lessons from the Crisis of 2008. Acta Oeconomica, 68(S): 45-70.

Varga, J. Z. (2016): The Effect of Interbank Liquidity on Corporate and Interbank Rates. Public Finance Quarterly, 61(1): 94-109.

Vogelsang, T. J. - Perron, P. (1998): Additional Tests for a Unit Root Allowing for a Break in the Trend Function at an Unknown Time. International Economic Review, 39(4): 1073-1100.

Wong, K. P. (1997): On the Determinants of Bank Interest Margins Under Credit and Interest Rate Risks. Journal of Banking and Finance, 21(2): 251-271.

Open Access. This is an open-access article distributed under the terms of the Creative Commons Attribution 4.0 International License (https://creativecommons.org/licenses/by/4.0/), which permits unrestricted use, distribution, and reproduction in any medium, provided the original author and source are credited, a link to the CC License is provided, and changes - if any - are indicated. (SID_1) 